\title{
CIÊNCIA COGNITIVA E MODELOS MENTAIS NO ENSINO DE ÉTICA
}

\section{Cognitive science and Mental Models for teaching ethics}

João Batista Magalhães Prates - Universidade Federal de São Paulo (UNIFESP)/Brasil

RESUMO: O texto que tens em mãos trata-se de uma aplicação do conceito de modelo mental ao ensino de ética em pelo menos dois ambientes: o empresarial e o escolar. Propõe-se formas mais eficientes do ensino e reflexão sobre a conduta nessa área que tem sido cada vez mais perquirida na medida em que parece haver um colapso moral generalizado em vários âmbitos da sociedade. Um dos problemas pode ser a falta de eficácia no ensino de normas feito através de memorização e não a partir da captação do seu sentido fundamental.

Palavras-chave: Ciência cognitiva. Ensino de ética. Filosofia da educação. Modelos mentais.

ABSTRACT: This paper is the main subject is how can we apply the concept os "mental model" to the teaching os ethics in at least two environments: the business and the school. We propose here more efficient methods of teaching and thinking about the conduct in this area that has been more and more investigated in this days of moral collapse. One of the problems can be the lack of efficiency in teaching the rules through mere memorization rather than through its fundamental meaning.

Keywords: Cognitive science. Ethics teaching. Educational Philosophy. Mental Models.

\section{INTRODUÇÃO}

Cognitivismo, que é o nome que se dá a uma abordagem teórica para o entendimento da mente humana que enfatiza as funções cognitivas inerentes ao aparelho mental e que, embora encontrem no ambiente e seus estímulos e experiências as ocasiões para se manifestar e desenvolver, tem uma existência algo independente e a priori com relação a esses estímulos do aprendizado. A teoria dos modelos mentais insere-se no interior da Ciência Cognitiva enquanto forma multidisciplinar de entender o(s) processo(s) pelo(s) qual(is) a mente humana conhece o mundo (nossa faculdade cognitiva, portanto). Apesar das várias formulações distintas de autores distintos, aqueles que apostam que os "modelos mentais" prestam-se a explicar melhor o processo concorda em que se tratam de mecanismos esboçados que representam mentalmente um estado de coisas. Quando procedemos às operações mentais complexas, lançamos mão de vários desses modelos sintetizados e dinâmicos/funcionais, que livram-nos da necessidade de

Educação, Psicologia e Interfaces, Volume 4, Número 2, p. 09-21, Abril/Junho, 2020.

ISSN: 2594-5343. DOI: 10.37444/issn-2594-5343.v4i2.186 
manter sob a memória cada um dos elementos que entram nos nossos processos mentais. A analogia com os sistemas computacionais é retomada no contexto várias vezes para explicar o funcionamento da nossa capacidade cognitiva: o cérebro é visto, a exemplo de um computador, como centro de cômputo de dados, transformando informações complexas em informações simples em linguagem própria (mentalês).

É impossível não associar tudo o que foi lido ao conceito de "categorias transcendentais do pensamento" kantiano, que seriam justamente as condições de possibilidade do nosso pensamento, trabalhada na Lógica enquanto elementos próprios do instrumento cognoscente (uma linguagem própria a partir da qual computamos ou codificamos os dados recebidos pela experiência dos sentidos). O problema fundamental do idealismo kantiano aqui é evitado, porém, pela suposição a priori de que - muito embora só tenhamos acesso a representações mentais do mundo - o mundo existe em si mesmo e nossos modelos mentais não são tão somente ativos, devendo construir uma representação da realidade com lastro na realidade dada na percepção. Tal síntese de representação ativa (construto mental da realidade) e percepção passiva (intuição da realidade como ela é) poderia achar no bergsonismo um aliado importante. Abstenho-me de perseguir aqui, neste texto introdutório, tais questões filosóficas, bastando identificar, com isso, a multidisciplinaridade inerente ao campo de pesquisa, que se encontra na intersecção de muitas áreas diferentes do conhecimento.

A investigação científica dos modelos mentaisencontra algumas dificuldades principais. Para além do misterioso funcionamento processual da mente, da qual ninguém conhece a linguagem própria, bem como do misterioso fenômeno da consciência, que nos obriga a intercalar sempre representações mentais entre nós e o objeto que tentamos conhecer (clássico problema do idealismo na Filosofia), resta o fato de que os modelos mentais (assim como todas as experiências mentais) são inescrutáveis na sua qualidade de experiência subjetiva interior. Soma-se a isso o fato da pessoalidade de cada modelo, havendo uma construção particular para cada indivíduo - o que os faz poluídos -; seu caráter quase sempre implícito/inconsciente, e no limite, a diafonia presente entre os teorizadores dos modelos mentais, que não atingiram consenso sobre os pormenores do fenômeno. Não obstante, a investigação é possível porque não se conclui disso um solipcismo radical e a inalcançabilidade do objeto; antes, esse conteúdo poderia ser estudado indiretamente, uma vez que haveriam vestígios intersubjetivos que nos 
forneceriam pistas da conformação individual desses modelos - numa solução fenomenológica clássica. Essas pistas compõem os principais documentos que vimos serem utilizados pelos cientistas da cognição: compilações de relatos e entrevistas, bem como demais produções simbólicas das pessoas estudadas. Além do mais, e apesar das diferenças teóricas, todos consentem sobre o caráter de representação funcional do real que os modelos adquirem. A investigação tem se dado, sobretudo, de maneira qualitativa no campo, tendo sido introduzido por exceção experiências de validação quantitativa, buscando um maior controle e rigor dos resultados. Porém, dada a variação infinita de modelos, é duvidoso que se possa estudar vastos grupos através de conceitos totalizantes e universais, sendo necessária uma abordagem e estudo caso a caso, que leve em conta a história e idiossincrasias de cada indivíduo. Talvez por isso as pesquisas costumem apresentar um número relativamente pequeno de sujeitos investigados.

O professor que quiser em sala de aula trabalhar com investigação de modelos mentais de seus alunos encontrará dificuldades de manejo. Entretanto, identificar os modelos mentais dos alunos "permite ao professor aprimorar a sua organização didática ao conhecer previamente pontos críticos na compreensão de determinado assunto e ao identificar a complexidade hierárquica de um tema sob perspectiva dos próprios alunos" (VIEIRA JÚNIOR, 2019, p. 17). Ao estabelecer uma hipótese sobre a evolução dos níveis de um modelo mental, o professor hierarquiza seu planejamento didático em etapas sucessivas ("progressão de dificuldade" imaginada). Daí, para que a aula seja bem sucedida e o assunto seja apreendido pelos alunos, tal hipótese deve verificar-se verdadeira, corroborada pela prática. Há chances de não sê-lo, entretanto, uma vez que ao elaborar o planejamento, o professor tende a projetar as suas próprias concepções das dificuldades possíveis. Por isso investigar a estrutura dos modelos mentais dos alunos, identificando possíveis universalidades, se apresenta como uma estratégia importante para guiar o planejamento de uma aula e das avaliações, uma vez que "aquilo que o professor considera como 'mais complexo' nem sempre reflete o mesmo sentimento dos alunos" (VIEIRA JÚNIOR, 2019, pg. 19). Tendo em vista também que aprender a operar com modelos mentais significa um ganho abstrativo-funcional, e que os alunos não modeladores serão repetidores que não se apropriam dos conceitos aprendidos, não produzindo aprendizagem/alteração cognitiva, faz-se urgente a investigação e trabalho 
com modelos mentais. É com esse objetivo em vista que passamos a analisar o estudo que se apresenta a seguir.

\section{ANÁLISE DE UM ESTUdO COM MODELOS MENTAIS NA EDUCAÇÃO}

\section{MORAL}

O artigo que analisaremos é intitulado "Ética corporativa: o uso de mapas mentais para o exercício da a responsabilidade corporativa", escrito pelas pesquisadoras Luciane Alves Vieira, Marcelle Rossi Brandão e Ana Carolina de Gouvêa Dantas Motta, todas ligadas à grande área da gestão de pessoas. O objetivo das autoras, como é colocado já no resumo, é analisar a eficácia da utilização dos modelos mentais nas empresas para o ensino e a apreensão pelos funcionários do Código de ética, que regulamenta a conduta esperada por eles. Nas palavras das autoras,

O treinamento dos Códigos de Ética das empresas visa o alcance da eficiência e o comprometimento de seus funcionários e sua direção na estabilidade e continuidade da finalidade proposta neste. $\mathrm{O}$ engajamento e conhecimento pelos diversos colaboradores, clientes, fornecedores e parceiros, viabilizam esta atuação pois propagam o estreitamento dos propósitos no combate aos desvios. [...] Para uma eficácia na aplicação do código de ética é necessário o comprometimento de todos (qualquer processo só terá efetivação quando todos se conscientizarem e participarem), a elaboração de um processo para avaliação de riscos (um estudo e analise de históricos e potencias desvios devem ser mapeados, discutidos e eliminados para não se tornarem uma não conformidade em potencial, desenvolvendo ações preventivas) e um programa de treinamento e comunicação efetivo (um processo eficaz de divulgação e treinamento do comportamento direcionado sempre analisando o ponto de vista da gestão e educacional) (VIEIRA; BRANDÃO; MOTTA, 2018, pp. 188).

Tal ensino-treinamento corporativo da ética (empresarial), embora focado na conformação de condutas consideradas adequadas ao ambiente de trabalho de cada empresa, não deixa de guardar semelhanças e se utilizar de conceitos da ética filosófica, disciplina escolar que figura no currículo do ensino básico para a Filosofia e inspira de longe essas práticas. A empresa, tal qual a escola, se apresenta como um protótipo da sociedade em que interagem pessoas e conhecimentos que necessitam ser aprendidos para a boa convivência. A pesquisa pretende, portanto, subsidiar a tarefa das empresas de ensinar seu código de ética aos empregados - e aqui se coloca a questão pela busca da eficácia do processo de ensino aprendizagem, uma vez que

Educação, Psicologia e Interfaces, Volume 4, Número 2, p. 09-21, Abril/Junho, 2020.

ISSN: 2594-5343. DOI: 10.37444/issn-2594-5343.v4i2.186 
Para eficácia da implantação do Código de Ética, toda empresa deverá estar comprometida com as normas desenvolvidas e sua manutenção, considerando medidas sancionais disciplinares para 0 seu descumprimento considerando também uma forma de recompensa pela disseminação e o atendimento deste por todas as áreas envolvidas. Sua implantação deve estar ligada diretamente a diretoria da empresa que deverá se fazer conhecer a todos os seus profissionais. Os profissionais devem conhecer seus deveres e direitos e ajudar a moldar o melhor plano para que este guia seja claro e consiga mostrar a verdadeira identidade da empresa e suas atividades. Missão e compromissos assumidos com as partes envolvidas (...) A aplicação do Código de Ética possibilita o fortalecimento da imagem da empresa junto a sociedade, aproximar os diversos profissionais da organização durante a elaboração do código ou do treinamento deste, tende a ser um instrumento para solucionar possíveis conflitos e problemas internos; auxilia na ordem e transparência pois proporciona mais coerência nas ações, transcreve a conduta moral da formação da empresa e a maneira que ela é conduzida; melhora da relação entre clientes, funcionários, fornecedores e até governo. Grande parte dos conflitos nas empresas são de cunho moral gerados por assedio, discriminação, corrupção e outras ações que atingem de forma negativa os objetivos do Código de Ética. (VIEIRA; BRANDÃO; MOTTA, 2018, pp. 5-7 grifos nossos)

Para fazê-lo eficazmente, é necessário que os sujeitos a que se quer conformar a boa conduta sejam

mapeados e estudados para a melhoria do processo de treinamento podendo-se utilizar várias ações e ferramentas para tornar o processo mais eficaz e efetivo. O conceito é prevenir o desvio conduzindo a conduta dos profissionais; detectar o desvio identificando os indícios e corrigir no sentido de tratar os desvios de forma coesa e transparente para atingir a eficiência do programa. Não conformidade são desvio que não podem ser tolerados (...) desenvolvimento dos processos, acompanhamento de sua aplicação, verificação de sua eficácia (...) mitigação do risco de desvios de conduta; intensificar o gerenciamento do risco (...) desenvolvimento de programas de conscientização dos profissionais (...) Em concordância com o processo o Código de Ética deve mensurar as ações profissionais, como atender o que prevê o código de ética, sendo executados treinamentos efetivos, a distância ou presencial com orientação de profissional qualificados (VIEIRA; BRANDÃO; MOTTA, 2018, pp. 6-7 - grifos nossos).

É para subsidiar esse ensino-treinamento que as autoras mobilizam a psicologia da educação e trabalhos de cientistas da cognição que operam com conceitos de modelos mentais com variações específicas sobre uma mesma ideia geral. Não é o caso de esmiuçar os sentidos específicos de cada conceito; basta assinalar a semelhança que eles guardam com as noções de "modelo mental" (individual e idiossincrático-funcional -

Educação, Psicologia e Interfaces, Volume 4, Número 2, p. 09-21, Abril/Junho, 2020.

ISSN: 2594-5343. DOI: 10.37444/issn-2594-5343.v4i2.186 
aquele que é construído pela pessoa em sua experiência cotidiana fora da academia e da relação com o método científico) e "modelo conceitual” (para o modelo mental construído pelo professor como subsídio do processo de ensino, que deveria refletir o real científico). A discussão recai aqui na necessidade de identificar os conceitos e valores que aparecem em um Código de ética específico de uma empresa (que fornece o conteúdo a ser ensinado - e que equivaleria ao dado do real que se quer representar em um modelo de ensino), ligá-los em um modelo conceitual orgânico e que seja significativo aos alunos. Daí a necessidade de conhecer os modelos mentais individuais daqueles que entrarão no processo de ensino, para quem os modelos conceituais são feitos.

Para elaboração do mapa cognitivo devem ser considerados não só o ambiente proposto ao indivíduo como também as experiências vivenciadas por este e a forma como são apresentados os conceitos. Os mapas tendem a ser construídos ou modificados conforme são conhecidos os conceitos e a forma como estes são apresentados aos indivíduos de acordo com a experiência vivida por estes deixando de ser apenas uma representação de sua percepção [...] Devido à dinâmica das mudanças de cenário e conceitos, os mapas tendem a uma constante modificação, pois as informações recebidas variam de intensidade de acordo com a necessidade do indivíduo, suas experiências passadas e suas expectativas quanto ao futuro. Quanto maior a necessidade de novas informações pelo indivíduo, maior será a mudança estrutural dos mapas de forma contínua. Os mapas apresentam de forma simplificada o ambiente de maneira imprecisa devido a dinâmica das mudanças, porém utilizam conceitos e padrões para sua construção (VIEIRA; BRANDÃO; MOTTA, 2018, pp. 14-15).

O próximo passo é o passo prático propriamente dito. Eis como as autoras sugerem que as empresas procedam na utilização dos mapas mentais para o ensino da ética no interior das corporações:

Estes mapas [individuais] são estruturados basicamente através de entrevistas [exatamente como vimos a pesquisa de modelos mentais nas leituras do curso] ou estudos organizacionais, não possui um modelo fixo, porem depende da imaginação do seu desenvolvedor para agrupar os conceitos a fim montar uma estrutura significativas e que evidencie as informações de forma clara e objetiva. [...] Tem-se a coleta dos dados, identifica-se os conceitos, apresenta-se estes aos indivíduos que irão aplicar os seus conhecimentos e suas experiências [constrói-se o modelo mental do indivíduo, chamado "mapas de identidade e de categorização" na tipologia das autoras] (...) A partir destes conceitos inicia-se o desenvolvimento do mapa [causal na tipologia das autoras; conceitual na tipologia do nosso curso] (VIEIRA; BRANDÃO; MOTTA, 2018, p. 15). 
O mapeamento individual que precede a construção do mapa conceitual-causal a ser ensinado é importante, segundo as autoras (e ainda numa mesma perspectiva que se nos apresentam os textos estudados até aqui nesta disciplina), porque

A partir do desenvolvimento do mapa, tem-se um processo de aprendizado pessoal e coletivo, conforme descrito por Bastos (2002) através da reflexão do indivíduo na aplicação de sua experiência e conhecimento. Com a categorização dos conceitos e mantendo a linguagem natural é possível desenvolver os mapas de identidade que possuem metodologias especificas [...] Quando se oferece essa liberdade de desenvolvimento ao indivíduo, pode-se verificar a diferencia de conhecimento e entendimento de cada indivíduo e quando este conhecimento é transportado para o coletivo, [...] este mapeamento pode ser intangível porem conectada e desenvolvida por outros indivíduos [...] A forma mais conhecida e desenvolvida nas empresas é o processo de mapeamento livre individual, para determinar o nível de conhecimento do conceito proposto e a partir destes resultados verificar a melhor combinação representativa do Código de Ética para um mapeamento direcionado (VIEIRA; BRANDÃO; MOTTA, 2018, p. 16).

A partir da última seção passa-se a descrever efetivamente como as pesquisadoras procederam para a construção de um modelo conceitual adequado às empresas para ensinar, a partir do confronto de três códigos de ética de três empresas diferentes, e aqui surge uma novidade iluminadora referente à pesquisa dos mapas individuais idiossincráticos:

Foram identificados conceitos correlatos nos Códigos analisados, para elaboração do modelo do mapa cognitivo e para este modelamento foi utilizada a ferramenta XMaind 6, onde foram dispostos os conceitos, procurando manter uma hierarquia no desenho do diagrama e seus relacionamentos, possibilitando assim uma visão ampla generalizada deste modelo Neste mapeamento direcionado a proposta seria apresentar ao indivíduo alguns conceitos, elementos e parâmetros para que o mapa cognitivo a ser desenvolvido esteja alinhado com os princípios e valores da empresa. Propondo um conceito geral de dois parâmetros considerados positivos e um negativo para a escolha do indivíduo, a escolha de parâmetros diferentes do proposto pelo Código de Conduta considerado negativo, este seja desenhado em vermelho para chamar atenção e abrir uma janela para explanação do porque aquele parâmetro estaria divergente da visão da empresa. Da escolha do indivíduo pelo parâmetro de acordo com o Código de Ética este seria representado na cor azul com uma breve explanação e apresentação do item deste. Os parâmetros referentes ao conceito proposto devem ser apresentados ao indivíduo para escolha em tempo simultâneo. Para que este conheça todas as oportunidades de escolha e os parâmetros

Educação, Psicologia e Interfaces, Volume 4, Número 2, p. 09-21, Abril/Junho, 2020.

ISSN: 2594-5343. DOI: 10.37444/issn-2594-5343.v4i2.186 
positivos podem ser contabilizados para evidenciar a eficácia do treinamento (VIEIRA; BRANDÃO; MOTTA, 2018, p. 17).

\section{SUGESTÕES RELEVANTES PARA A PRÁTICA DOCENTE}

As autoras utilizaram um software computacional para proceder à pesquisa dos modelos mentais individuais em jogo, atuantes nos sujeitos da aprendizagem. A existência destes instrumentos automatiza a pesquisa individual que poderia mostrar-se complexa de levar a cabo em uma sala de aula com muitos alunos. Podem somar-se aos esforços de aplicação de questionários já validados e contornar o caso de não existirem para o mapeamento de algum assunto específico em uma disciplina qualquer. Pesquisar a oferta dessas possibilidades pode ser precioso ao professor que busca conhecer como pensam os seus alunos a respeito do tema que deve ensinar, para poder apresentá-los com eficácia um percurso de apreensão do modelo conceitual construído. Outra preciosa sugestão está na organização de uma forma dinâmica de ensino, que alia os ganhos da interatividade autodidata, com mecanismos ativos e participativos além de imagéticos. A tecnologia se apresenta como aliada da tarefa:

A utilização de mapas cognitivos utilizados como ferramenta no treinamento do Código de Ética das Empresas propõe um conceito de aprendizagem onde o indivíduo pode ou não interagir com o processo de desenvolvimento destes e pode ser aplicado entre indivíduos ou grupos de determinadas áreas afins. A proposta é a criação de um cenário onde os indivíduos possam transcrever para estes esquemas as suas experiências e o seu conhecimento, considerando que a área de aplicação destes mapas está em constante modificação, o mapeamento do processo para desenvolvimento das ações de comportamento direcionado deverá ser analisada constantemente, pois existem mutações nas diversas épocas e os avanços tem que ser acompanhados Porem deve-se verificar que por mai diferenças que hajam entre os indivíduos sobre suas experiências e conceitos, um dos pontos principais deste mapeamento e mostrar claramente aos indivíduos os princípios e valores da empresa durante a representação dos esquemas desenvolvendo estruturas que possam ajudar na compreensão das decisões e ações que os configuram. Hoje é possível analisar uma série de técnicas utilizadas e discutidas por diversos autores da área para desenvolvimento dos mapas, para tanto a empresa pode verificar qual a técnica mais viável para aplicação do seu processo estrutural, considerando as diversas adversidades desta (VIEIRA; BRANDÃO; MOTTA, 2018, pp. 17- 18).

Feitas as adequações de conteúdo e objetivo, podemos inspirar-nos nesta experiência para proceder ao ensino da ética na Filosofia, tendo por base de construção

Educação, Psicologia e Interfaces, Volume 4, Número 2, p. 09-21, Abril/Junho, 2020.

ISSN: 2594-5343. DOI: 10.37444 issn-2594-5343.v4i2.186 
dos modelos conceituais não os códigos de ética das empresas, mas os conceitos dos cânones da Filosofia Moral.

\section{APRESENTAÇÃO DE UM APLICATIVO EDUCACIONAL PARA O ENSINO DE DIREITOS HUMANOS}

Pesquisando pela rede mundial de computadores pode-se encontrar a página de um projeto realizado pelo Senac com o apoio da Palas Athena e da UNESCO que disponibiliza um jogo virtual gratuito para trabalhar a temática dos direitos humanos. $\mathrm{Na}$ descrição, lemos:

O jogo apresenta algumas etapas: faz inicialmente uma breve contextualização histórica dos direitos humanos. A seguir, os alunos organizados em grupos fazem a escolha do avatar que os representará nas etapas seguintes, sendo a primeira um Quiz com questionamentos sobre a Declaração Universal dos Direitos Humanos; e a segunda uma sequência de 12 missões que apresentam uma manchete de um jornal do futuro (por isso o nome Diário de Amanhã), noticiando a violação de direitos humanos presentes no cotidiano das pessoas na localidade em que vivem, no mundo do trabalho, ou no mundo virtual. Os alunos devem fazer a escolha de uma opção que evite que a notícia vire um fato. Estimula-se assim a análise e reflexão sobre as situações buscando um posicionamento frente a elas de modo que cada pessoa encontre no seu cotidiano um jeito de colocar em prática o que vai expresso na Declaração Universal dos Direitos Humanos e de não se calar frente as injustiças que testemunha ${ }^{1}$.

Sabendo como as tecnologias educacionais se mostram instrumentos eficazes de ensino, ajudando a fixar modelos mentais quando interativos, expondo o aluno ao trabalho com múltiplos sentidos e lhes dando imagens dos processos, indicaremos o aplicativo para subsidiar o ensino de Filosofia, na temática geral "ética e filosofia política", para trabalhar conteúdos vários, sobretudo atitudinais e conceituais - especialmente o de "alteridade" e "empatia". Recomenda-se o jogo para alunos alfabetizados de qualquer idade, devido à maneira como ele se apresenta, mediado por linguagem farta e diretivas. Está disponível para qualquer plataforma que possua "adobe flash player" e está em português, o que facilita em muito a sua dimensão e capacidade comunicativa e interativa

\footnotetext{
${ }^{1}$ http://www.palasathena.org.br/noticia_detalhe.php?noticia_id $=184$
}

Educação, Psicologia e Interfaces, Volume 4, Número 2, p. 09-21, Abril/Junho, 2020.

ISSN: 2594-5343. DOI: 10.37444/issn-2594-5343.v4i2.186 
para jovens e adultos. Sendo também muito iconográfico, mediado por videos e imagens com sons agradáveis e chamativos.

\section{PROPOSTA METODOLÓGICA PARA USO}

O próprio aplicativo traz em seu "menu" um manual de instruções para que o professor possa aplicar o jogo. Ele deve ser conhecido. Uma vez na posse do jogo baixados nos celulares dos alunos, em computadores da sala de informática ou mesmo em um único computador conectado a projetor audiovisual em sala de aula -, os alunos serão convidados a ler com o professor o menu de instruções para os alunos, embutido no aplicativo, e irão configurando a sala para a aplicação da proposta conforme a leitura (dividindo-se em grupos, escolhendo avatares e nomes e confeccionando os demais materiais necessários para o início do jogo, conforme a descrição das instruções).

Para dar sequência ao jogo, o professor só deverá interferir para explanar conceitos nos momentos adequados, em que se apresentam histórias e se leem enunciados - que precedem todas as ações do jogo. A sua continuidade é bastante intuitiva. As missões tratam cada uma de uma temática específica a partir dos 26 artigos da Declaração Universal dos Direitos do Homem. Pretende-se trabalhar a partir deste jogo conteúdos tanto conceituais como atitudinais - e mesmo os procedimentais (no caso, com a compreensão da estrutura do Estado democrático de direito e das instâncias de direitos humanos da ONU, bem como dos processos pelos quais se pode acionar as portas de entrada de ambos para fazer valer um direito ou denunciar um abuso). Os conceitos mais salientes dizem respeito ao pensamento ético, jurídico e político e as atitudes, de cooperação e solidariedade (para falar em termos de um filósofo clássico na área de estudos, Jeremy Bentham, deve-se aprender o princípio da "igual consideração de direitos").

O jogo além de ser entremeado por linguagem e se fundar a partir do debate reflexivo e da escolha autônoma dos alunos, exige a posição do professor como tão somente guia e catalisador de reflexões e exposição mais detalhada e aprofundada de conteúdo que será apropriado para uso do aluno, o que conforma o seu caráter comunicacional no sentido freireano e possibilita aos alunos trabalharem efetivamente com manipulação e construção de modelos mentais. Sugere-se que em ambiente empresarial ferramenta semelhante seja desenvolvida ou adotada para maximizar os

Educação, Psicologia e Interfaces, Volume 4, Número 2, p. 09-21, Abril/Junho, 2020.

ISSN: 2594-5343. DOI: 10.37444/issn-2594-5343.v4i2.186 
resultados. O desafio para essas empresas é operar com os instrumentos necessários à boa prática educacional e com professores ou tutores bem formados e capazes de explicitar as causas últimas e a conexão causal que apresente a ética enquanto ciência fundamentada, e não apenas como cartilha desprovida de conteúdo e sentido (arbitrária, portanto) à qual se deve simplesmente obedecer por medo de punição. Tal concepção insulta a inteligência do aluno que só pode desacatar e nutrir desprezo pelas regras de conduta. Além do mais custa dinheiro preparar um processo eficaz, a nível empresarial e escolar, de ensino de ética e filosofia - o que em certa medida contradita toda a ênfase na redução de custos que assola a realidade capitalista.

\section{OUTRAS FORMAS DE INTERATIVIDADE E AUTONOMIA NA APRENDIZAGEM}

O estado da arte tecnológica nos permite experiências de realidade virtual onde os alunos possam viver "na pele", em primeira pessoa, as situações descritas como dilemas e limites da ética. Uma cena de tortura, por exemplo, poderia ser vivenciada - desnutrida de seu elemento principal, evidentemente, poderia ainda receber, pela construção do cenário e as situações em sala pelo professor, todos os elementos cinestésicos, sonoros, visuais e os odores da lúgubre situação. Lembro-me de uma experiência em meus tempos de ensino básico quando visitamos um museu para aprender sobre a escravidão brasileira. Fomos conduzidos a uma sala que reproduzia um navio negreiro. Ficaram todos os alunos tão apertados na sala que não conseguiam mexer um único braço; elementos visuais e sonoros compunham uma cena representativa que já anunciava a realidade virtual e a imersão que a mais alta tecnologia pode promover nos dias de hoje. Pode-se também compor as situações descritas com videos de depoimentos reais de pessoas implicadas nas situações de ferimento de direitos humanos que se descrevem - direta ou indiretamente. Visitas a locais em que se verifiquem violações explícitas dos direitos humanos (penitenciárias ou casas de repouso; comunidades carentes e lixões etc) poderiam ser estimuladas também - e aqui a realidade virtual e as experiências de imersão em $360^{\circ}$ podem ajudar bastante quando da impossibilidade ou risco da presença física em tais lugares. Tudo isso estimula a compreensão empática por parte do aluno e fundamenta a concepção de que a conduta deve ser regrada para evitar abusos de toda espécie.

Educação, Psicologia e Interfaces, Volume 4, Número 2, p. 09-21, Abril/Junho, 2020.

ISSN: 2594-5343. DOI: 10.37444/issn-2594-5343.v4i2.186 
Uma outra ideia é elaborar diretrizes para que o professor conduza laboratórios de debate teórico para a aplicação e confronto de teorias morais diferentes que fundamentam certas formas de se ver os direitos, justificando o dever-ser daqueles que reconhece. Os alunos serão levados a perceber que, a depender de sua vinculação teórica com pensadores e correntes da ética (utilitarismo, kantismo, bergsonismo etc), alguns direitos serão defendidos e outros não. Esse exercício os fará perceber as consequências práticas de um modo de conceber a ética e então a defesa dos direitos humanos poderá transcender a esfera da lei instituída e adentrar o espaço que a precede, a saber, o campo da legitimidade da construção da lei de uma forma ou de outra. No campo da ética propriamente dita, portanto. Esse movimento adentraria de forma mais incisiva a área da Filosofia, aprofundando em seus debates específicos.

\section{CONSIDERAÇÕES FINAIS}

Por fim, a proposta holística de ensino de ética aqui defendida, na mesma medida em que pode contribuir para solidificar comportamentos, pode ter o efeito contrário de obrigar as empresas a rever todas as normas de conduta que seriam imediatamente identificadas pelos alunos assim tornados capazes de reflexão, de sua falta de fundamento, arbitrariedade e mesmo injustiça. Tudo leva a crer que tais normas de conduta e etiqueta empresarial não podem, em última instância, ser reconhecidas pela mesma alcunha da disciplina filosófica da Ética, uma vez que a contradita.

\section{REFERENCIAS BIBLIOGRÁFICAS}

ARISTÓTELES. Ética a Nicômaco. Os Pensadores, São Paulo: Abril Cultural, 1984.

BENTHAM, Jeremy. Uma introdução aos princípios da moral e da legislação. Os Pensadores, São Paulo: Abril Cultural, 1984.

BERGSON, Henri. As duas fontes da moral e da religião. RJ: Zahar Editores, 1978.

MILL, Stuart. Sôbre a Liberdade. São Paulo: Companhia Editora Nacional, 1942.

PLATÃO. A república. Tradução de J. Guinsburg. São Paulo: Perspectiva, 2012.

RAWLS, John. Uma teoria da justiça. São Paulo: Martins Fontes, 2002.

ROUSSEAU, J. J. Do contrato social. São Paulo: Abril Cultural, 1978.

RYDER, R. D. Painism: A Modern Morality. United Kingdom: Open Gate Press, 2001.

Educação, Psicologia e Interfaces, Volume 4, Número 2, p. 09-21, Abril/Junho, 2020. 
VIEIRA JÚNIOR, N. Ciências Cognitivas na Educação. Arcos, Curso de PósGraduação em Docência, disciplina Ciência cognitiva na Educação, 2019, (Material não publicado).

VIEIRA. Alves, L.; BRANDÃO. Rossi, M.; MOTTA. Dantas, A. C. G. Ética corporativa: o uso de mapas mentais para o exercício da a responsabilidade corporativa. P2P \& INOVAÇÃO, Rio de Janeiro, v. 5 n. 1, p.156-176, Set./Fev. 2018. Disponível em: http://revista.ibict.br/p2p/article/view/4372/3758 Acesso em: 1 de setembro de 2019.

\section{Credenciais do autor}

PRATES, João Batista Magalhães. Graduado em Filosofia (UNIFESP); Mestrando em Filosofia (UNIFESP).

Endereço para correspondência: João Batista Magalhães Prates. Rua Bento Araújo, 149, Barro Branco. CEP: 02345040, São Paulo/SP. Email: batistaprates1 @ gmail.com

Como citar este artigo (Formato ABNT): PRATES, João Batista Magalhães Prates. Ciências cognitivas e modelos mentais no ensino de Ética. Educação, Psicologia e Interfaces, v. 4, n. 2, p. 09-21, 2020. Doi:10.37444/issn-2594-5343.v4i2.186

Recebido: 07/10/2019.

Aceito: $20 / 02 / 2020$ 